\title{
Evaluation of a Shuttle Derived Vehicle (SDV) for Cargo Transportation
}

\author{
Jose M. Roman ${ }^{*}$, Stephen B. Meacham ${ }^{\dagger}$, Donald R. Krupp ${ }^{\ddagger}$, G. E. Threet ${ }^{\S}$ and Joel Best ${ }^{* *}$ \\ NASA George C. Marshall Space Flight Center, Marshall Space Flight Center, AL 35812 \\ Stephan R. Davis ${ }^{\dagger \dagger}$ and Christopher Crumbly ${ }^{\ddagger \ddagger}$ \\ NASA Headquarters, Washington, DC 20546 \\ Ronald A. Olsen ${ }^{\S \S}$ and Leah M. Engler ${ }^{* * *}$ \\ Morgan Research Corporation, Huntsville, AL 35805 \\ Tim Garner $^{\dagger \dagger \dagger}$ \\ United Space Alliance, Huntsville, AL 35806 \\ and \\ Joseph S. Fawaz \\ Hernandez Engineering, Incorporated, MSFC, AL 35812
}

In this new era of space exploration, a host of launch vehicles are being examined for possible use in transporting cargo and crew to low Earth orbit and beyond. Launch vehicles derived from the Space Shuttle Program (SSP), known as Shuttle Derived Vehicles (SDVs), are prime candidates for heavy-lift duty because of their potential to minimize nonrecurring costs and because the Shuttle can leverage off proven high-performance fight systems with established ground and flight support. To determine the merits of SDVs, a detailed evaluation was performed. This evaluation included a trade study and risk assessment of options based on performance, safety/reliability, cost, operations, and evolution. The purpose of this paper is to explain the approach, processes, and tools used to evaluate launch vehicles for heavy lift cargo transportation. The process included defining the trade space, characterizing the concepts, analyzing the systems, and scoring the options.

\footnotetext{
* Senior Systems Engineer, Space Transportation Programs and Projects Office, Systems Engineering and Integration, Requirements Management, NP22, MSFC, and a non-member.

+ Aerospace Engineer, Space Transportation Programs and Projects Office, Systems Engineering and Integration, NP23, MSFC, and a non-member.

¥ Technical Coordinator, Vehicle Integration and Performance Analysis, EV12, MSFC, and a member.

Aerospace Engineer, Space Transportation Programs and Projects Office, Advanced Concepts, NP12, MSFC, and a non-member.

** Operations Engineer, Engineering Directorate/Mission Operations Laboratory, Operations Engineering and Concept Development, EO04, MSFC, and a non-member.

${ }^{\dagger \dagger}$ Project Manager, Exploration Systems Mission Directorate, Requirements Division, NASA Headquarters, and a senior member.

$\ddagger$ Cargo Launch Vehicle Study Manager, Space Transportation Programs and Projects Office, NP01, MSFC, and an active member.

$\$$ Principal Engineer, Space Transportation Programs and Projects Office, Exploration and Transportation Systems Development Office, NP70, MSFC, and a non-member.

*** Senior Analyst, Space Transportation Programs and Projects Office, Exploration and Transportation Systems Development Office, NP70, MSFC, and a non-member.

${ }^{\dagger+}$ Senior Systems Engineer, Space Shuttle Propulsion Office, Systems Engineering and Integration, MP71, MSFC, and a non-member.

${ }^{+1+}$ Senior Project Assurance Engineer, Safety and Mission Assurance, QD01, MSFC, and an active member.
}

1

American Institute of Aeronautics and Astronautics 
The process also included a review by subject experts from NASA and industry to compare past and recent study data and assess the risks. A set of technical performance measures (TPMs) was generated based on the study requirements and constraints. Tools such as INTROS and POST were used to calculate performance, FIRST was used for prediction of reliability, and other software packages, both commercial and NASA-owned, were applied to study the trade space. By following a clear process and using the right tools a thorough assessment was performed. An SDV can be classified as either a side-mount vehicle (SMV) or an in-line vehicle (ILV). An SMV is a Space Shuttle where the Orbiter is replaced by a cargo carrier. An ILV is comprised of a modified Shuttle External Tank (ET) with engines mounted to the bottom and cargo mounted atop. For both families of vehicles, Solid Rocket Boosters (SRBs) are attached to the ET. The first derivate of Shuttle is defined as the vehicle with minimum changes necessary to transform the Space Shuttle into an SDV. Deltas from the first derivate were also formulated to study more SDV options. Examples of deltas include replacing the SRBs with larger and/or more SRBs, adding an upper stage, increasing the size of the ET, changing the engines, and modifying the elements. Challenges for SDV range from tailoring infrastructure to meeting the exploration schedule. Although SDV is based on the Space Shuttle, it still includes development risk for designing and building a Cargo Carrier. There are also performance challenges in that Shuttle is not optimized for cargo-only missions, but it is a robust system built on reusability. Balancing the strengths and weaknesses of the Shuttle to meet Lunar and Mars mission objectives provides the framework for an informative trade study. SDV was carefully analyzed and the results of the study provide invaluable data for use in the new exploration initiative.

\section{Nomenclature}

$\begin{array}{ll}\text { ATO } & =\text { Abort to Orbit } \\ \text { DDT\&E } & =\text { Design, Development, Test, and Evaluation } \\ \text { ET } & =\text { External Tank } \\ \text { ETT } & =\text { Exploration Task Team } \\ \text { FOM } & =\text { Figure of Merit } \\ \text { GR\&A } & =\text { Ground Rules and Assumptions } \\ \text { ILV } & =\text { In-line Vehicle } \\ \text { JSC } & =\text { Johnson Space Center } \\ \text { KSC } & =\text { Kennedy Space Center } \\ \text { LCC } & =\text { Launch Control Center } \\ \text { LEO } & =\text { Low Earth Orbit } \\ \text { LES } & =\text { Launch Escape System } \\ \text { MCC } & =\text { Mission Control Center } \\ \text { MLP } & =\text { Mobile Launch Platform } \\ \text { mET } & =\text { Modified External Tank } \\ \text { MSFC } & =\text { Marshall Space Flight Center } \\ \text { RSRM } & =\text { Redesigned Solid Rocket Motor } \\ \text { RSRB } & =\text { Reusable RSRM/SRB } \\ \text { SDV } & =\text { Shuttle Derived Vehicle } \\ \text { S\&MA } & =\text { Safety and Mission Assurance } \\ \text { SMV } & =\text { Side-mount Vehicle } \\ \text { SRB } & =\text { Solid Rocket Booster } \\ \text { SSC } & =\text { Stennis Space Center } \\ \text { SSME } & =\text { Space Shuttle Main Engine } \\ \text { SSP } & =\text { Space Shuttle Program } \\ \text { TPM } & =\text { Technical Performance Measure } \\ \text { VAB } & =\text { Vehicle Assembly Building } \\ \text { VIPA } & =\text { Vehicle Integration and Performance Analysis }\end{array}$




\section{Introduction}

$\mathrm{T}$ He Space Shuttle system is comprised of a flight segment and a non-flight segment. The flight segment, as shown in Fig. 1, includes the Orbiter, the External Tank (ET), two Solid Rocket Boosters (SRBs), and two Redesigned Solid Rocket Motors (RSRMs). Note: The SRB/RSRM combination is commonly referred to as the SRBs, but, for this study, they are referred to as RSRBs. The Space Shuttle non-flight segment is comprised of ground and flight operations.

A Shuttle Derived Vehicle (SDV) for cargo transportation, as shown in Fig. 2, is a launch vehicle system that utilizes flight and non-flight elements from the Space Shuttle Program (SSP), with the exception that the Orbiter is

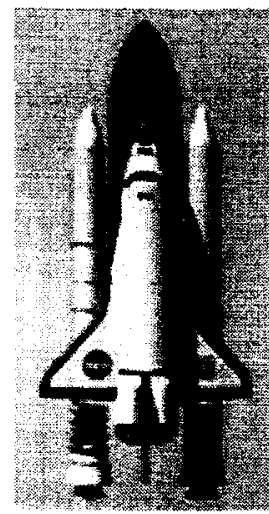

Figure 1. Shuttle not used. Parts of the Orbiter are utilized, but the Orbiter as a whole is not used because the Space Shuttle system is limited to lift of approximately 22 metric tons (mT) of cargo to low Earth orbit (LEO), as compared to the Saturn V that lifted $51 \mathrm{mT}$, not including the third stage or the launch escape system (LES). Note: The Apollo third stage weighed $119 \mathrm{mT}$ and the LES weighed $4 \mathrm{mT}$.

In lieu of the Orbiter, SDV employs a carrier structure called the Carrier to accommodate cargo. The difference in weight between the Orbiter and the Carrier, not including payload (crew and cargo), is approximately the difference in payload-carrying capacity. For example, if the wings were removed from the Orbiter, more weight could be kept on the books as payload. Given that the SDV Carrier is quite different from the Orbiter, a significant amount of analysis was performed and more analysis is required to fully characterize the differences between Shuttle and SDV.

SDVs are good heavy-lift vehicle candidates because of their potential to minimize development cost and because the Shuttle propulsion system has a demonstrated high performance. The intent of this study was not to show that an SDV is better or worse than non-SDV options, but to accumulate the necessary data for integration into a Lunar launch vehicle system study and to help develop a system of systems and launch vehicle requirements relevant to exploration as a whole.

Within the SDV family, there are some very important trades and studies that could be key to the success of exploration requirement development. The SDV baseline concept is a Space Shuttle where the Orbiter is replaced by the Carrier. The SDV family tree includes many variants of Shuttle, but, in this study, a limited set of vehicles is selected that envelops the trade space. The trade space is mapped from modest-lift capability (greater than Shuttle) to heavy-lift options.

The SDV family also includes In-line Vehicles (ILVs). An ILV, as shown in Fig. 3, is comprised of a set of RSRBs and a modified ET (mET). An mET has engines mounted on one end and a cargo carrier/shroud mounted atop its forward section. The heaviest lift variants of SDV could employ larger than standard RSRBs, additional RSRBs, and upper stages. Lower-lift options include the SDV baseline and SDVs with less numbers of engines or different main

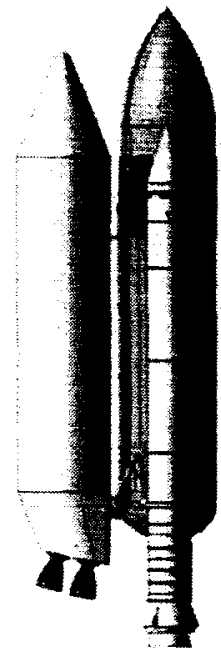

Figure 2. SDV engines.

\section{Operations Considerations}

SDV operations are largely based on the SSP. The primary exception is that SDV for cargo does not require provisions for crew, therefore infrastructure and systems related to crew operations are not required. The other basic difference is processing the Carrier instead of the Orbiter.

Flight hardware similarities common to SSP and SDV include RSRBs, ETs, and engines. Variations of RSRB includes using more than two RSRBs per flight, using a 5-segment SRM in lieu of the currently used 4-segment SRM, and employing non-reusable SRBs as compared to the reusable SRBs used by the SSP. Modifications to the ET for the SDV side-mount vehicle (SMV) depend on the degree of changes, if any. For the IIV, the ET must be redesigned to accommodate new attachment structures for the engines and the payload shroud support. Other possible changes include modifications to the main engines or replacing the Space Shuttle Main Engines (SSMEs) with another type of engine.

SDV will be able to use the SSP ground infrastructure such as the SSP production facilities, processing facilities (SRB, Orbiter/Carrier, payload, and engines), the launch pads, mobile launch platforms, the Vehicle Assembly Building (VAB), vehicle transporters, and ground support equipment. The degree of modifications to the ground infrastructure depends on the differences betwcen the Shuttle and the SDV. At a minimum, some changes are 
required to the VAB, launch pad, and the Mobile Launch Platform (MLP) in order to accommodate the differences between the Orbiter and the Carrier. A new vehicle transporter is needed for the Carrier. The Crawler Transporter should not require any modifications. Some changes are expected for payload processing and other changes for conversion from Orbiter processing to Carrier processing. Few changes, if any, are expected for SRB and SSME processing. SSME processing at the Kennedy Space Center (KSC) may not be necessary if all the SSME work normally done at KSC can be performed at the Stennis Space Center (SSC).

Flight operations similarities include the Launch Control Center (LCC), ground software and range safety. For SDV, a single LCC, probably the LCC at KSC, would be responsible for the launch vehicle through its entire mission. The Mission Control Center (MCC) in Houston or another Lunar payload control center would be responsible for the payload once deployed from the launch vehicle. The bascline study also assumed that LCC software will be re-written for maintenance purposes and will conform to future standards. Range safety is not expected to be different from the current SSP requirements.

Production of SDV flight elements should also be the same as Shuttle. Upgrades and changes to the infrastructure may apply for modified flight elements and the ILV elements. Also, there exists a possibility that changes in approach and processes could be instituted to save cost.

\section{Exploration Schedule Considerations}

Schedule considerations are based on the risks associated with developing a system to meet its initial capability date. Given that the President's vision supports a human mission to the Moon as early as 2014, the more development and technology activities required, the higher the risk. For SDV, development risk items include an ILV, a 5-segment RSRB, upper stages, and modified SSME.

Other considerations include transitioning from the SSP to the SDV program. Return to flight of the Shuttle, remaining Shuttle missions, and maintaining the capability to manufacture Shuttle components are the primary transition issues.

\section{Approach, Processes and Tools}

The SDV study was performed in two parts. The intent of the first part was to evaluate the multiple options that span the trade space. In the second part, the baseline concept was analyzed in greater detail. This approach helped produce a significant amount of data to support Exploration Constellation Systems planning and requirements development.

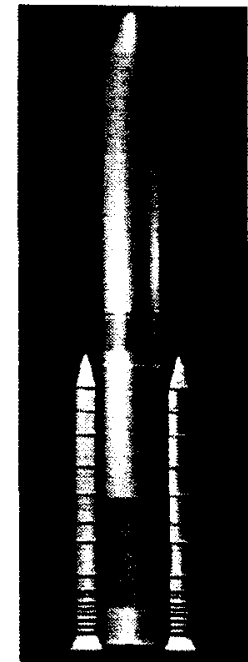

Figure 3. ILV.

The basic study plan included a risk assessment and evaluation of SDV options via a set of figures of merit (FOMs). The risk assessment was performed by an independent team of subject experts. The FOMs include performance, safety, cost, and evolution. The specific FOM for performance was lift capability; for safety, it was probability of loss-of-vehicle and loss-ofmission; and cost was split into system development cost and annual operations cost. Evolution was a special case in which vehicle options were assessed to determine possible spiral paths. For example, a spiral path for a baseline SMV could be the replacement of 4-segment RSRBs with 5segment RSRBs. This would allow an SDV to operate as early as possible while the 5-segment RSRB is still being developed.

The process included identifying, analyzing, and scoring the options based on the FOMs. The purpose for scoring was not to determine which option was the best, but to understand each option's sensitivity to performance, reliability, and cost.

The study of operations was also critical to the overall study. The operations analysis was used to calculate operations cost, assess changes to the infrastructure, and identify areas of improvement. Also, operations is important because each mission may require multiple launches. In other words, can the current SSP system support two or more launches in tandem as required by mission constraints? If not, what changes are required to the operations infrastructure? Given that mission requirements are not known at this time, the study focused on a parametric approach to determine the breakpoints and quantify both sides of the breakpoints.

The analysis process is shown in Figure 4. The first step in the process was defining the input data and the last step was reporting key findings. The critical path included defining, analyzing, costing, and scoring the concepts. Non-critical path items included assessing risk, analyzing excursions, reviewing similar studies, and generating the development schedule.

Throughout the study, several milestone reviews were conducted. The purpose of the first review was to validate the irade space and cvaluate preliminary performance results. The second review was used to report the findings of 
part one of the study. The third and last major review was focused on the reexamination of the baseline concept in order to provide a more in-depth understanding of SDV.

Three teams were formed to execute the study. The teams included an SDV core team, the data integration team, and the risk assessment team. The core team derived the trade space and managed the study. The integration team rolled up the data, helped ensure data consistency, and generated the sensitivity studies. The risk assessment team reviewed the concepts and derived technical, programmatic, and schedule risks. The integration team also coordinated with other teams to ensure consistency across the Agency and to ensure the proper transition of the results to the super study. A chief engineer also resided over the process to maintain technical accuracy.

In the second part of the SDV study, a group from industry represented by Boeing, Lockheed Martin, United Space Alliance, and ATK Thiokol joined the team. The industry team in conjunction with the Government team coordinated a data exchange for the purpose of comparing results. The results were compared and the differences were documented and later converted into future-work recommendations.

The SDV team was supported by two strong analytical teams, the MSFC Advanced Concepts group and the Vehicle Integration and Performance Analysis (VIPA) team. They performed different aspects of the vehicle performance analyses. NASA Safety and Mission Assurance (S\&MA) generated the reliability predictions and supported risk identification. The SSP provided key technical data and oversight. The vehicle performance team developed models and aero databases. They generated mass properties, trajectory data, and other performance data such

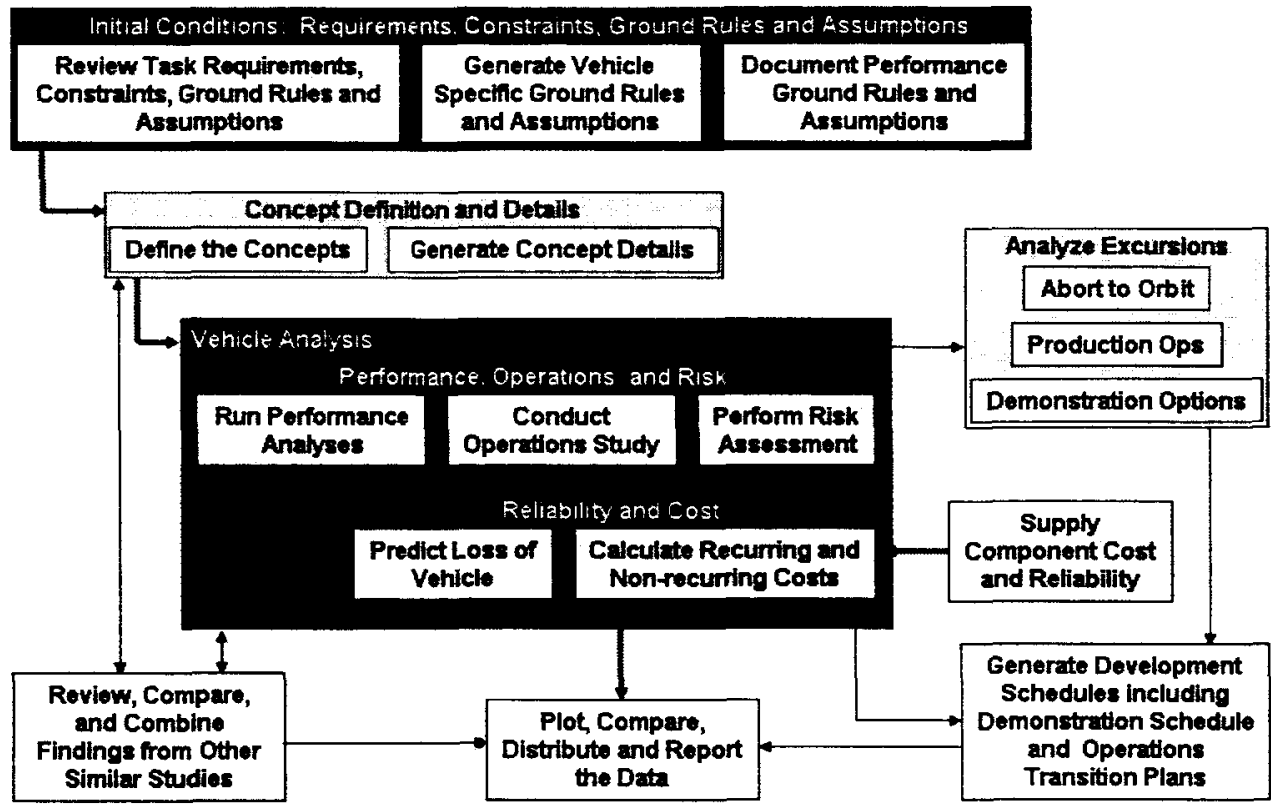
as thermal and stress.

Some results were supported by wind tunnel data from the old Shuttle-C Program.

The computer model for the SMV included a detailed concept of the Carrier. The Carrier concept included the main propulsion system, thrust structure, reaction control system, payload adapter, structural load bearing parts, ET attachments, payload release mechanism, fairing, fairing opening/release mechanisms, and avionics. The analysis team in cooperation with the concepts design team performed sensitivity analyses to address differences in design options for payload attachment, payload release, load bearing, overall size, and materials such as aluminum vs. composites. Performance runs were completed for many configurations for both the SMV and ILV.

Tools used to calculate mass properties, trajectory, and other performance data included POST and INTROS. The tool used to calculate the overall vehicle concept reliability was FIRST.

The following steps outline and further define the approach and process:

\section{A. STEP I - Requirements, Constraints, Ground Rules, and Assumptions}

The analysis process was based on the requirements and constraints of the task request. The task request also provided a set of ground rules and assumptions (GR\&A). In addition to the GR\&As, a specific set of GR\&As were developed for SDV. Prior to the start of the performance analyses, a performance and sizing working group documented a common set of performance GR\&As, such as the aerodynamics/environments database.

\section{B. STEP II - Concept Definition}


The chosen concepts were based on an agreed-to trade space. For each concept, a definition was composed that characterized the vehicle's major elements such as its engines, motors, and tanks. Some concepts were less detailed than others, but, at a minimum, sizes, weights, and interfaces were understood as well as load-bearing structures, thermal protection systems, and estimates for subsystems. For the SMV options, concepts for the payload carriers were developed. Figure 5 provides a concept for payload deployment operations.

\section{STEP III - Performance, Operations, and Risk}

Based on the initial conditions and concept definitions, performance analyses were run, operations studies were conducted, and risk assessments were completed. The main products from performance, operations, and risk were payload weight, infrastructure impacts, and top risks, respectively.

\section{STEP IV - Reliability and Cost}

Using the output data from the performance analyses (trajectory, design, and payload weight), the probability of loss of vehicle was predicted for each concept. Using the output data from the performance analyses (system data and weights), proposed production changes for vehicle propulsion elements, and launch site infrastructure modification analysis, the non-recurring/design, development, test, and evaluation (DDT\&E) costs were estimated. Using the output data from the operations assessment (infrastructure and usage) and reliability analysis, the recurring/life cycle costs were calculated.

\section{E. STEP V - Analysis Excursions: Abort to Orbit, Production Operations and Flight Demonstration}

The concept definitions, analyses, and operations provided a basis for analysis of abort to orbit (ATO) scenarios. Several of the concepts in the trade space assumed that an engine could be lost at the moment of liftoff, therefore the intent of the ATO excursion analysis was to determine how much payload must be off-loaded in order to reach orbit. Other ATO scenarios included running engines at higher operational levels at

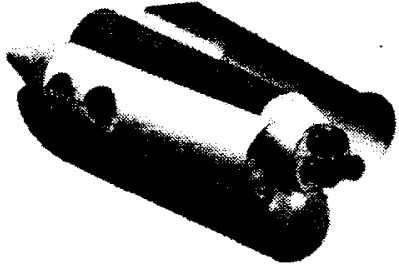

Figure 5. Payload Deployment. the moment when an engine is lost and off-loading payload. The ATO analysis process included defining a vehicle and a scenario and then determining the net payload that a vehicle could carry to orbit. Teams at Johnson Space Flight Center (JSC) and Marshall Space Flight Center (MSFC) completed the ATO analyses.

Production operations is a subset of recurring operations. Given that the production of vehicles is a major cost driver, an investigation of possible cost savings was performed. The specific process included obtaining information for each launch vehicle element, documenting the production flow, identifying cost drivers, and listing the steps and vehicle components that have potential for cost savings. The industry team was very helpful in providing this data.

Flight demonstration of an SDV was a constraint in the study. The way in which this item was studied was by solicitation of ideas from NASA and industry, determining the merit and feasibility of each idea via critique by subject experts, and gathering input from the Operations and the Shuttle offices. A schedule of the primary option was prepared, including respective pros and cons. Alternative demonstration possibilities were also documented.

\section{F. STEP VI - Comparisons and Checks: Industry Study}

Some portions of the study were reinforced and complimented by a review and comparison of similar studies. The results from Part I, dated May 2004, were compared to an industry study. These results were also compared to data generated at JSC. The comparison process included presenting results, comparing results, documenting differences, determining if the differences were significant, and recommending forward work.

\section{G. STEP VII - Development Schedule}

Based on knowledge from the entire study, a development schedule was generated. The timeline encompassed formulation to first flight. Other facets of development included Shuttle phase out and the shutdown of manufacturing capabilities.

\section{H. STEP VIII - Data Summary, Distribution, and Comparisons}

The final step in the study was compiling the output data for each vehicle and cataloging select parametric data and Technical Performance Metrics (TPMs) for comparison. Comparison data included payload weight, reliability and cost. This information was provided to the Exploration Task Team (ETT) integration team study for inclusion 
in a more thorough inclusive vehicle system study where Lunar mission system FOMs were based on the TPM values. Comparison data was generated and documented in a report.

\section{Space Shuttle System Considerations}

SDV has unique attributes that were studied and traded. The intent of this study was to complete the evaluation of these unique attributes and/or generate sufficient data as input for the next study. Example of attributes include the only reusable operational engine in history (i.e., the SSME, see Fig. 6), the largest solid rocket ever built and flown, and an extensive infrastructure for launching. All of these attribuies were not fully addressed, but sufficient technical data needed to perform a comparison with other options was provided.

An In-line SDV is part of a special family of SDV vehicles. They are unlike the Shuttle vehicle because they do not require a side-mounted Orbiter or Carrier. ILV also has a greater potential to evolve by adding a fourth main engine, a different upper stage, more SRBs, or an extended ET. The payload is mounted atop the ET, which is similar to the mounting approach used by expendable vehicles such as Atlas and Delta. The primary commonalities with Shuttle systems include the propulsion elements, SSMEs, SRBs, and ET technology, and some of its infrastructure facilities.

SDV operations that are uncommon with Shuttle include the use of expendable SSMEs, limited flight operations, no crew, no Orbiter, therefore no landing operations, and other ground infrastructure differences such as SDV cargo processing.

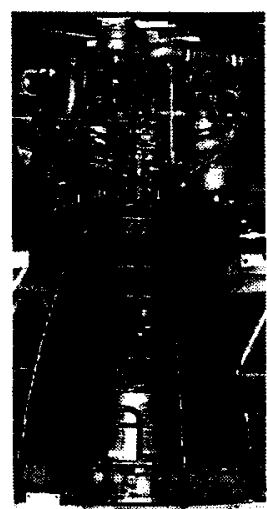

Figure 6. SSME.

\section{Conclusion}

Space Shuttle offers the possibility of delivering cargo to orbit for the express purpose of exploration. There exists a possibility that Shuttle can be converted into a cargo-only type vehicle called Shuttle derived. A Shuttle derived vehicle for cargo transportation consists of multiple vehicle options. The objective of the SDV study was to evaluate each option and provide the data to be used in a Constellation Systems Lunar mission launch vehicle study.

The approach and process used in the study included definition of the trade space, concept definition, cargo carrier design, performance analysis, reliability predictions, operations evaluation, cost estimating, sensitivity analyses, risk assessment, and comparison with other studies. A significant amount of data was generated, plotted, compared, and reported. A set of FOMs was applied to support the sensitivity analyses. An operations considerations document was generated to compare SDV to Shuttle operations. A team of experts at NASA and industry joined forces to validate the data. Reports were forwarded to the Exploration Systems Mission Directorate, Constellation Systems, for use in helping to formulate exploration road map possibilities and requirements.

\section{Acknowledgments}

The SDV study was a cooperative effort between the NASA Marshall Space Flight Center, AL, the Johnson Space Flight Center, TX, and the Kennedy Space Flight Center, FL.

Special thanks to the Space Shuttle Propulsion Office, MSFC; the Launch Operations Team, KSC; Ruth Harrison, SDV task Deputy Manager, KSC; David Anderson, Chief Engineer; MSFC, the Advanced Concepts Group, MSFC; the Vehicle Integration and Performance Analysis Team, MSFC; the JSC SDV team, JSC; the Space Science Applications International Corporation (SAIC), reliability and performance analysis teams, Huntsville, AL; the Industry Team, Boeing, Lockheed Martin, United Space Alliance and ATK Thiokol; and the Independent Risk Assessment Team, MSFC.

\section{References}

Reports

${ }^{1}$ Davis, S. R. and Engler, L., "Task 5: Shuttle Derived Vehicles", NASA, May 2004.

${ }^{2}$ Crumbly, C., "Cargo Launch Vehicle Input", NASA, August 2004.

${ }^{3}$ Best, J., Barley, B., Newhouse, M. and Guffin, T., "Operations Considerations for Shuttle Derived Side-Mount Cargo Launch Vehicle Concept Trade Study" NASA FD04-04-001, September 2004.

${ }^{4}$ Meacham, S., Roman, J. and Delacruz, M. "Cargo Vehicle Concepts Analysis" NASA, September 2004.

${ }^{5}$ Olsen, R., Fawaz, J. and Feth. S, "Shuttle Derived Vehicle (SDV) Study" NASA, September 2004.

${ }^{6}$ Krupp, D. and the Vehicle Integration and Performance Analysis Team, "Shuttle-Derived Vehicle: Side-Mounted Configuration Integrated Vehicle Baseline Characterization", NASA, September 2004.

${ }^{7}$ Threet, G. E. and Brady, H. "Inline STS Derived Launch Vehicle (Magnum)" NASA, February 2004. 